\title{
Assessment of child car safety and parental knowledge
}

\section{N.Kavlashvili, I.Chkhaidze, M.Kherkheulidze, E.Kandelaki -TSMU, lashvili Childrens Central Hospiral, Tbilisi, Georgia}

AlM: The goal of the study was to assess the child car safety and parental awareness about it through the parent's special questionnaire.

METHODS: The study was conducted in 2016-2017 at Child Development Center of lashvili Children's Central Hospital. 181 parents of children aged 0 to 8 years were interviewed. Data were analyzed using SPSS16.

RESULTS: Results show that only $23.9 \%$ of children travel safely, in $76.1 \%$ of cases the safety issues are neglected. Younger parents (less than 25 years) are more likely to use of child passenger safety restraints (33.3\%) than the middleaged $(26.7 \%)$ and older (13.6\%) parents. The difference was statistically significant only between young and middle aged parents $(P=0.0235)$. Child safety seats were used more frequently in infants less than 6 month (37.2\%). As for children more than 4 years, in all cases (100\%) safety rules are not neglected. Parents from urban area (39.1\%) were using child restrain system compared to parents from rural areas $(8.9 \%)(P<0.0001)$. Parents' educational status had no influence on keeping child safety issues $(P=0.0965)$. As for the source of information about child car safety, non of parents has received any information from the primary health care providers or any other medical personnel, media is the main source of information.

CONCLUSION: It is desirable to conduct a large survey that will give us more accurate data. Parents should be informed about child car safety issues. Increasing knowledge of medical personnel and providing information on the importance of consultation on child care safety.

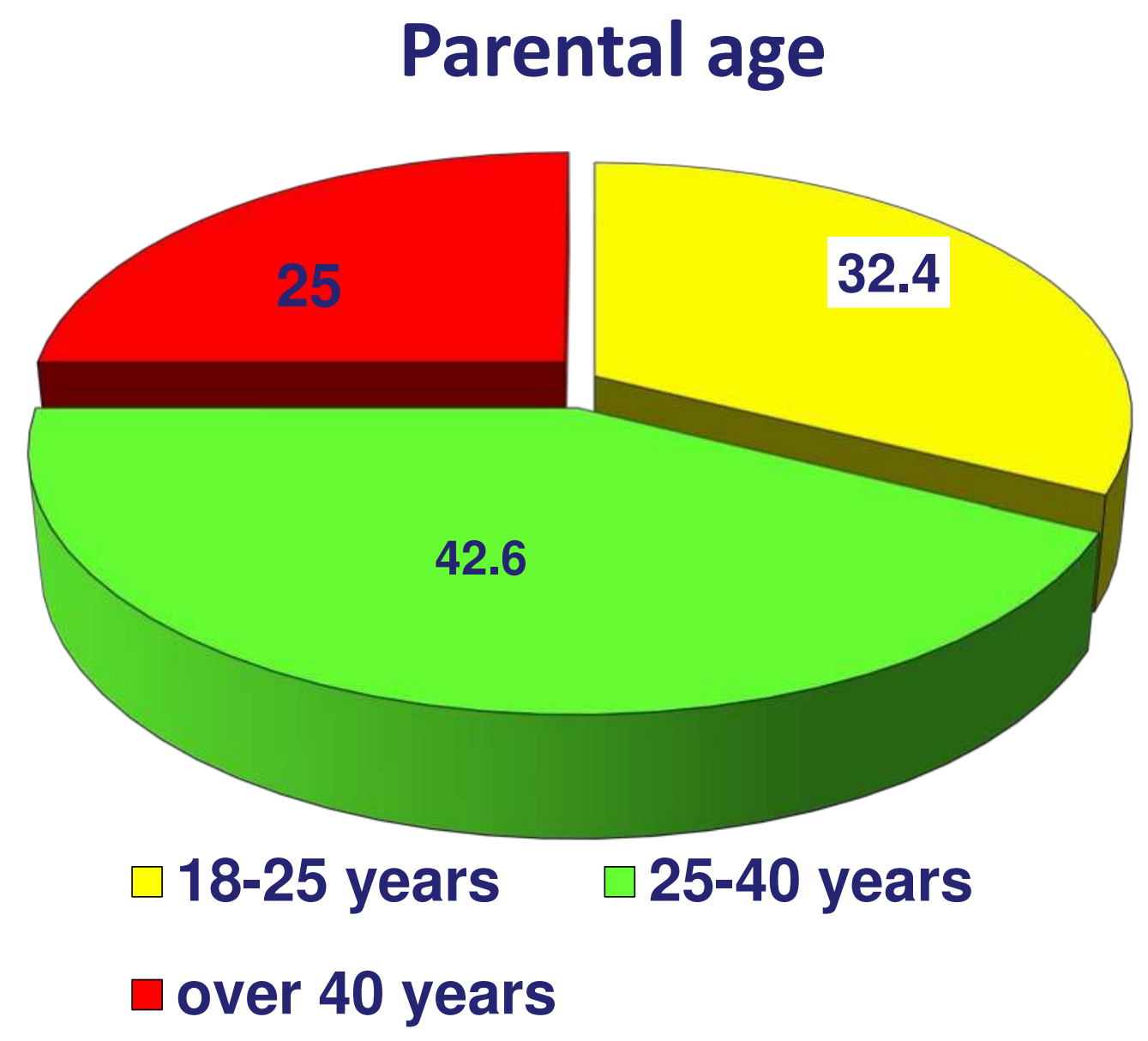

\section{Children age}

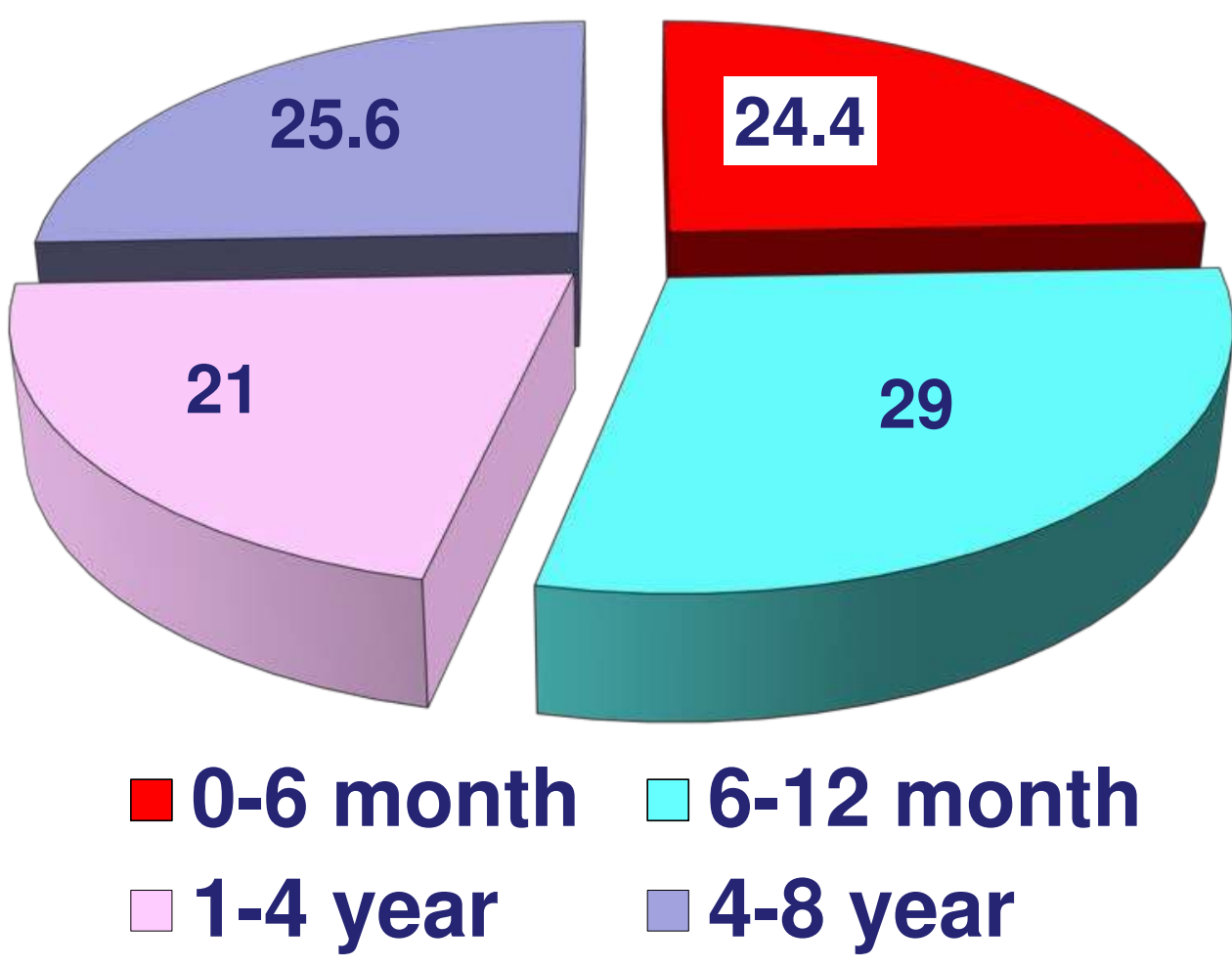

